\title{
Positive Anti-GABAB Receptor Antibodies in a Patient with Hashimoto's Thyroiditis and Bipolar Affective Disorder
}

\author{
Polina A. Sobolevskaia ${ }^{a}$ Boris V. Andreev ${ }^{b}$ Leonid P. Churilova, c \\ Tamara V. Fedotkina $^{a, d}$ Boris Gilburd ${ }^{a}$ e $\quad$ Aliya K. Stanova ${ }^{a}$ Vladimir J. Utekhin $^{a}$ \\ Yehuda Shoenfeld ${ }^{\mathrm{a}, \mathrm{b}}$

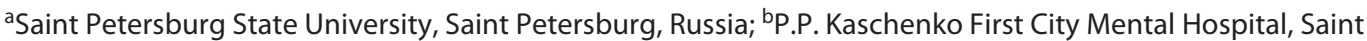 \\ Petersburg, Russia; 'Saint Petersburg Scientific Research Institute of Phthisiopulmonology, Saint Petersburg, Russia; \\ dSechenov Institute of Evolutionary Physiology and Biochemistry, Russian Academy of Sciences, Saint Petersburg, \\ Russia; 'Zabludowicz Centre for Autoimmune Diseases, H. Sheba Medical Center, Tel Hashomer, Israel
}

\section{Keywords}

Hashimoto's thyroiditis - Psychiatric disorders · Bipolar affective disorder · Autoimmunity

\begin{abstract}
A kind of autoimmune encephalitis with positive autoantibodies toward the B1 subunit of the gamma-aminobutyric acid-type $B$ receptor is known as anti-GABABR encephalitis. It is an autoimmune brain disorder with typical manifestations of a limbic encephalitis. It can coexist with positive anti-thyroid autoantibodies. We described a 57-year-old woman who was diagnosed with a bipolar affective disorder. The patient had high titers of anti-thyroid peroxidase antibodies, and she also was positive for anti-GABABR antibodies. There is a question, if this case is a kind of comorbidity of anti-thyroid and anti-brain autoimmunity or is it a single nosological entity - a kind of Hashimoto's encephalopathy?

(C) 2021 The Author(s)

Published by S. Karger AG, Basel
\end{abstract}

karger@karger.com www.karger.com/dmj

Karger $\stackrel{\text { ' }}{5}$

BOPEN ACCESS
(C) 2021 The Author(s)

Published by S. Karger AG, Basel

This is an Open Access article licensed under the Creative Commons Attribution-NonCommercial-4.0 International License (CC BY-NC) (http://www.karger.com/Services/OpenAccessLicense), applicable to the online version of the article only. Usage and distribution for commercial purposes requires written permission.

\section{Introduction}

Anti-GABAB receptor autoantibody is one of the reasons for autoimmune encephalitis manifested in shortterm memory loss, behavioral disturbances, confusion, and seizures, which can be diagnosed as a psychiatric entity [1-3]. At the same time, thyroid hormones render inhibiting effects on the activity of the GABAergic system. Liu et al. [4] showed that alteration of GABAergic neurotransmission can be an essential link in the pathogenesis of primary hypothyroidism, with regard to its psychoneurological manifestations [3].

It is also known that patients with GABAB receptor autoantibodies may be also positive for glutamic acid decarboxylase 65 (GAD65) autoantibodies, GNA/SOX 1 autoantibodies (typical for some paraneoplastic neurological syndromes as well), and, finally, positive for various anti-thyroid autoantibodies [4]. Anti-recoverin autoantibodies can be positive in some cases of paraneoplastic neurological syndromes and are usually associated with 
cancer-induced retinopathy $[5,6]$. In the case reported here, we have found positive paraneoplastic autoantibodies, positive anti-GABAB receptor autoantibodies, and positive anti-thyroid autoantibodies.

\section{Case Report}

Patient L., a 57-year-old woman, was hospitalized in a psychiatric hospital with a diagnosis of bipolar affective disorder due to current severe depressive episode. For the first time, the patient's mental state changed in the summer of 2010, when she began to feel frequent episodes of extremely good mood, being overactive, sociable, but often conflicted, annoyed, made impulsive purchases, and even falsified documents at work. In the autumn of the same year, the patient's mood began to decline; she felt guilty for falsifying documents and was afraid of being fired. There was a decrease in appetite, sleep disturbance, apathy, inactivity, and conflicts with others.

In January 2011, the patient attempted suicide twice, after which attempts she was admitted to a psychiatric hospital, where she was treated for 3 months. Two weeks after discharge, the patient again attempted suicide. After the attempt, she was again hospitalized in a psychiatric hospital. A few weeks later, the patient was discharged from the hospital with the following supporting outpatient treatment: clomipramine ${ }^{\circledR} 75 \mathrm{mg}$ and carbamazepine ${ }^{\circledR} 600 \mathrm{mg}$ daily. From 2011 to 2017, the patient constantly visited a psychiatrist, with noticeable improvement under treatment. In December 2017, her condition deteriorated again. She did not leave the home, stayed in bed and noted lack of appetite and tearfulness. From December 2017 to April 2018, she was treated in a psychiatric hospital and discharged with recommendations to take olanzapine ${ }^{\circledR} 20 \mathrm{mg}$.

The patient noted an improvement in her condition and mood and started to communicate easier with other people. But, after 2 months, the patient's condition worsened again, and she became apathetic and inactive. She experienced attacks of anxiety, fear, and anorexia. The patient was again hospitalized in a psychiatric hospital.

At the time of admission to the hospital, the patient was oriented in time, place, and self. She manifested anxiety-depressive symptoms, oligothymia, ideatory retardation, sleep disturbance, anxiety, attacks of fear, daily fluctuations of affect with worsening in the morning, dyssomnia disorders like early insomnia, and autoaggressive actions (scratching on the scalp). She was diagnosed with a bipolar affective disorder and a current depressive episode. The patient received antipsychotics quetiapine ${ }^{\circledR} 200 \mathrm{mg}$ once daily and Zalasta ${ }^{\circledR} 10 \mathrm{mg}$ twice a day and an anxiolytic (bromdihydrochlorphenylbenzodiazepine ${ }^{\circledR}$ $2.0 \mathrm{~mL}$ by intravenous injections twice a day).

The laboratory data revealed increased serum level of anti-TPO antibodies $-206.96 \mathrm{U} / \mathrm{mL}$ (upper normal range $-30 \mathrm{U} / \mathrm{mL}$ ), the concentration of TSH was elevated $-3.92 \mathrm{mIU} / \mathrm{mL}$ (normal range $0.3-4.0$ ), thyroxine concentration was normal $-58.92 \mathrm{nmol} / \mathrm{L}$ (normal range 52-155), and the level of tri-iodothyronine was 2.46 $\mathrm{nmol} / \mathrm{L}$ (normal range 1.2-3.0). Prolactin concentration was above the normal range for menopause $-811.2 \mathrm{mIU} / \mathrm{mL}$ (normal range 40-550). The patient was diagnosed with Hashimoto's autoimmune thyroiditis in accordance with the criteria of the Japanese Thyroid Association (JTA) [7]. Since the patient had a psychiatric disorder in combination with Hashimoto's autoimmune thyroiditis, she was included in the cohort of our study of autoimmune mechanistic links of thyroid-associated mental disorders.

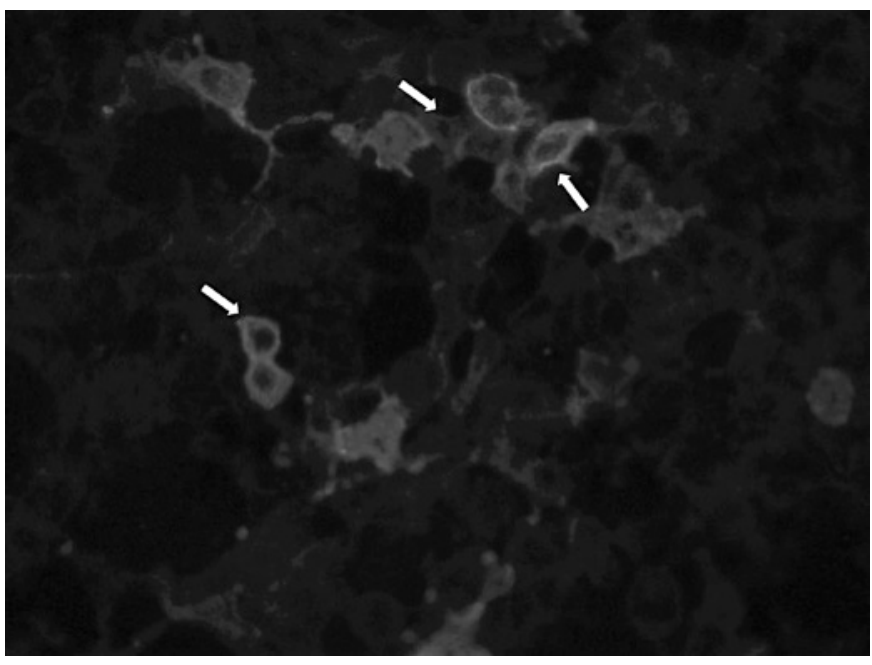

Fig. 1. The result of a positive stain for anti-GABAB receptor antibodies. Slides were evaluated by the indirect immunofluorescent method using an OLYMPUS BX43 microscope at excitation 480 $\mathrm{nm}$ and emission $510 \mathrm{~nm}$ (magnification, $\times 40$ ). The patient's serum was diluted $1: 10$ in PBS $0.2 \%$ Tween 20 .

Her blood serum was tested by the indirect immunofluorescent method for additional IgG autoantibodies associated with paraneoplastic neurological syndromes including those against the following 12 antigens: amphiphysin, CV2, PNMA2 (MA2/Ta), Ri, Yo, $\mathrm{Hu}$, recoverin, SOX1, titin, Zic4, GAD65, and Tr (DNER) (EUROLINE Autoimmune Encephalitis Mosaic 1; Euroimmune, Germany). The serum was positive for autoantibodies to recoverin only.

The patient's blood serum was also tested for several autoantibodies associated with autoimmune encephalitis by cell-based indirect immunofluorescence assay (Autoimmune Encephalitis Mosaic 1; Euroimmune, Germany). The autoantibodies against the following neural antigens were checked: glutamate receptor type NMDA, contactin-associated protein 2, glutamate receptors type AMPA 1, leucine-rich glioma-inactivated protein 1, glutamate receptors type AMPA 2, and $\mathrm{GABA}_{\mathrm{B}}$ receptor. The serum was positive for antibodies to GABAB receptors only (Fig. 1).

\section{Discussion}

Anti-GABABR encephalitis makes up to $5 \%$ of all cases of limbic encephalitis [8]. In the world literature, growing amount of anti-GABABR encephalitis cases has been mentioned recently. In many cases of anti-GABABR encephalitis, anti-thyroid autoantibodies and some paraneoplastic neural autoantibodies can be revealed $[9,10]$. It is also known that patients with GABAB receptor antibodies may be positive for GAD65 autoantibody and GNA/SOX 1 autoantibody (both are common in paraneoplastic neurological syndromes) $[4,9]$. 
Thus, the patient was diagnosed with bipolar affective disorder and Hashimoto's thyroiditis. At the same time, her tests for anti-GABABR and anti-recoverin autoantibodies also were positive (although the latter is uncommon in anti-GABABR encephalitis). The patient was treated for 7 years with antipsychotics and antidepressants, albeit the treatment was not successful, and she had frequent relapses of her mental disease. That probably means that the treatment was not pathogenetic because autoimmune encephalitis in the patient could be missed in this case under the mask of bipolar affective disorder. The patient needed additional diagnostic procedures, such as MRI (to find cerebral active foci). In addition, she needed probably corticosteroids, IVIG, or plasma exchange. It is worthy to emphasize that the patient was treated by antipsychotics, which can cause hyperprolactinemia [11]. This could be a reason for torpidity of the case to treatment. It is known that prolactin promotes the development of autoimmunity and autoimmune diseases as a systemic, paracrine, and autocrine immunostimulant, and thus hyperprolactinemia can be an immunopathogenic factor contributing to the appearance and progression of autoimmune diseases, according to the vicious circle principle [12].

\section{Conclusion}

Thus, if the patient had been diagnosed with Hashimoto's thyroiditis and was positive for anti-GABABR antibodies, hyperprolactinemia could worsen the course of her autoimmune disorder.

\section{Statement of Ethics}

The study has been approved by the Ethics Committee of the Saint Petersburg State University. A written informed consent was obtained from the patient for publication of this case report and any accompanying images.

\section{Conflict of Interest Statement}

The authors have no conflicts of interest to disclose.

\section{Funding Sources}

This work was supported by the grant of the Government of the Russian Federation for the state support of scientific research carried out under the supervision of leading scientists, agreement 14.W03.31.0009. Scientific research was performed at the Center for Molecular and Cell Technologies of Research Park of St. Petersburg State University.

\section{Author Contributions}

P.A.S. prepared the manuscript, performed the literature review, and performed laboratory studies. B.V.A. collected the data and reviewed the manuscript. L.P.C. reviewed and edited the manuscript. T.V.F. performed the literature review. B.G. performed laboratory studies. A.K.S. performed laboratory studies. V.J.U. performed the literature review. Y.S. reviewed and edited the manuscript.

\section{Data Availability Statement}

All data generated or analyzed during this study are included in this article. Further enquiries can be directed to the corresponding author.

\section{References}

1 Esposito S, Principi N, Calabresi P, Rigante D. An evolving redefinition of autoimmune encephalitis. Autoimmun Rev. 2019;18:155-63.

2 Höftberger R, Titulaer MJ, Sabater L, Dome B, Rózsás A, Hegedus B, et al. Encephalitis and $G A B A B$ receptor antibodies: novel findings in a new case series of 20 patients. Neurology. 2013;81:1500-6.

3 Boronat A, Sabater L, Saiz A, Dalmau J, Graus F. GABA (B) receptor antibodies in limbic encephalitis and anti-GAD-associated neurologic disorders. Neurology. 2011;76:795800.

4 Liu B, Yang H, Gao F, Wanga Q, Zhao B, Gong $\mathrm{T}$, et al. Investigation of brain GABA+ in primary hypothyroidism using edited proton MR spectroscopy. Clin Endocrinol. 2017; $2: 256-62$.
5 Shiraga S, Adamus G. Mechanism of CAR syndrome: anti-recoverin antibodies are the inducers of retinal cell apoptotic death via the caspase 9-and caspase 3-dependent pathway. J Neuroimmunol. 2002;1-2:72-82.

6 Honnorat J, Antoine JC. Paraneoplastic neurological syndromes. Orphanet J Rare Dis. 2007;2:22.

7 Akamizu T, Amino N. Hashimoto's thyroiditis. In: Feingold KR, Anawalt B, Boyce A, Chrousos G, de Herder WW, Dhatariya K, et al., editors. Endotext [Internet]. South Dartmouth (MA): MDText.com, Inc.; 2000.

8 Lancaster E, Martinez-Hernandez E, Dalmau $\mathrm{J}$. Encephalitis and antibodies to synaptic and neuronal cell surface proteins. Neurology. 2011;77(2):179-89.
9 Li C, Liu X, Wang R, Chen C, Zhou D, Hong Z. Encephalitis with antibodies against the $\mathrm{GABAB}$ receptor: high mortality and risk factors. Front Neurol. 2019;10:1030.

10 Zhang X, Lang Y, Sun L, Zhang W, Lin W, Cui L. Clinical characteristics and prognostic analysis of anti-gamma-aminobutyric acid-B (GABA-B) receptor encephalitis in Northeast China. BMC Neurol. 2020;20(1):1.

11 Bostwick JR, Guthrie SK, Ellingrod VL. Antipsychotic-induced hyperprolactinemia. Pharmacotherapy. 2009;29(1):64-73.

12 Stroev YI, Churilov LP. Sluchay besplodnogo braka, svyazannyy s autoimmunnym tiroiditom i klinicheski bessimptomnoy makroadenomoy gipofiza (prolaktinomoy) (a case of infertile couple associated with autoimmune thyroiditis and clinically asymptomatic pituitary macroadenoma [prolactinoma]). Clin Pathophysiology. 2016;22(1):72-9. 